\title{
Abdominal pregnancy: mini review
}

\section{Introduction}

Abdominal pregnancy is very rare condition of an ectopic pregnancy, defined as pregnancy occurring anywhere within the peritoneal cavity, exclusive of tubal, ovarian, or broad ligament. ${ }^{1}$ An estimated incidence is 1 in 8,000 births and $1.4 \%$ of whole an ectopic pregnancies. ${ }^{2}$ The most common implanting of abdominal pregnancy is Pouch of Douglas, but very rarely it may implant in the upper abdomen. ${ }^{3}$ However, implantation on other abdominal organs such as spleen, liver, and appendix is also reported. ${ }^{4,5}$ Therefore the diagnosis of abdominal pregnancy, Studdiford's criteria description include:

a) Typical normal both side fallopian tubes and ovaries

b) No utero-pertonial fistula

c) Pregnancy-related to the peritoneal surface and early enough the possibility of secondary implantation followed by a primary location in the tube. ${ }^{6}$

The maternal mortality range varies from $2 \%$ to $30 \%$, but this percentage can be further reduced by early diagnosis. ${ }^{7}$ If there is no cardiac activity in the fetus, then surgical approach is indicated here because of the complications such as infection or hematological disorders such as disseminated intravascular coagulation (DIC).

Some of gynecologists may recommend a period of observation of 3 to 8 weeks to allow atrophy to occur in placental vessels. ${ }^{8}$ If there is cardiac activity in the fetus, laparotomy is highly recommended, independent of gestational age or fetal condition. ${ }^{9}$ One of the most recent therapeutic approaches include ultrasonography guide injections such as methotrexate without need for exploratory laparotomy, it will lead in a gradual resorption of the products of conception without complications. ${ }^{10}$ However, there is a publication from Ghana that there is abdominal pregnancy that result in a full term baby at Regional Hospital. ${ }^{11}$

The proper management of abdominal pregnancy depends on the suspension of the physician, especially if nothing seen in ovaries, tubes and broad ligament. Actually, US and B-HCG sometimes can help to reach the diagnosis. The laparoscopic approach plays an important role if an ectopic pregnancy cannot be seen or ruled out, then all the abdomen should be seen including all the organs. If the diagnosis still vague we can use another approach such as MRI or intraoperative US. ${ }^{12}$

\section{Acknowledgments}

None.

\section{Conflicts of interest}

The authors declare no conflicts of interest.

\author{
Volume 10 Issue 2 - 2019
}

\author{
Mufareh Asiri,' Fatimah A Alzahrani² \\ 'Associated consultant, OB/GYN, King Saud Medical City, Saudi \\ Arabia \\ ${ }^{2}$ Medical Intern, King Klalid University, Saudi Arabia
}

Correspondence: Mufareh Asiri, Associate Consultant, University King Saud Medical City, Riyadh, KSA, Saudi Arabia, Tel 00966553725252, Email dr.mufareh@yahoo.com

Received: October 27, 2018| Published: March 15, 2019

\section{References}

1. Martin JN, Sessums JK, Martin RW, et al. Abdominal pregnancy: current concepts of management. Obstet Gynecol. 1988;71(4):549-557.

2. Nama V, Gyampoh B, Karoshi M, et al. Secondary abdominal appendicular ectopic pregnancy. J Minim Invasive Gynecol. 2007;14(4):516-517.

3. Yadav R, Raghunandan C, Agarwal S, et al. Primary hepatic pregnancy. $J$ Emerg Trauma Shock. 2012;5(4):367-369.

4. Nama V, Gyampoh B, Karoshi M, et al. Secondary abdominal appendicular ectopic pregnancy. J Minim Invasive Gynecol. 2007;14(4):516-517.

5. Yagil Y, Beck-Razi N, Amit A, et al. Splenic pregnancy: the role of abdominal imaging. Ultrasound Med. 2007;26(11):1629-1632.

6. King M, Bewes PC, Cairns J, et al. Abdominal pregnancy in primary surgery. 2014.

7. Strafford JC, Ragan WD. Abdominal pregnancy: review of current management. Obstet Gynecol. 1977;50(5):548-552.

8. Meinert J. Advanced ectopic pregnancy including combined ectopic and intrauterine pregnancy. Geburtshilfe Frauenheikd. 1981;41:490-495.

9. Maas DA, Slabber CF. Diagnosis and treatment of advanced extrauterine pregnancy. S Afr Med J. 1975;49(48):2007-2010.

10. Mitra AG, LeQuire MH. Minimally invasive management of 14.5-week abdominal pregnancy without laparotomy: a novel approach using percutaneous sonographically guided feticide and systemic methotrexate. J Ultrasound Med. 2003;22(7):709-714.

11. Baffoe P, Fofie C, Gandau BN. Term abdominal pregnancy with healthy new born: a case report. Ghana Med J. 2011;46(2):81-83.

12. Nilesh Agarwal, Funlayo Odejinmi. Early abdominal ectopic pregnancy: challenges, update and review of current management. The Obstetrician and Gynaecologist. 2014;16:193-198. 